\title{
Tecnologia da informação na gestão da cadeia de suprimentos: 0 caso da indústria gases
}

\author{
Renata Albergaria de Mello Bandeira UFRGS \\ Antonio Carlos Gastaud Maçada UFRGS
}

\section{RESUMO}

A Tecnologia da Informação (TI) contribui para tornar a logística mais eficiente e efetiva na geração de valor para as empresas. Como resultado, são inúmeros os sistemas de TI disponíveis para a aplicação na logística. Entretanto, os profissionais de logística nem sempre têm conhecimento sobre o melhor sistema a adotar segundo as características da cadeia de suprimentos. Este é um problema que, se não for eliminado, poderá impedir a materialização das promessas trazidas pela combinação do conceito de gestão da cadeia de suprimentos (SCM) e TI. Assim, o escopo desta pesquisa consiste em identificar as principais tecnologias de informação empregadas na gestão da cadeia de suprimentos do setor de gases industriais. Seis variáveis estratégicas - Integração, Custos de Armazenagem, Custos de Movimentação, Velocidade, Competitividade e Coordenação Interorganizacional - são empregadas para analisar os impactos do investimento em TI na SCM de gases industriais. Os resultados indicam que a variável estratégica organizacional Integração tem maior impacto sobre o uso da TI, seguida pela Competitividade, Custos de Transporte e Velocidade.

\section{PALAVRAS-CHAVE}

Tecnologia da Informação, gestão da cadeia de suprimentos, variáveis estratégicas organizacionais.

\section{Impact of information technology in supply chain: the case of the gas industry}

\begin{abstract}
Information Technology (IT) contributes towards making logistics more efficient and effective in the generation of value within a company. As a result, there are numerous IT systems available for application in logistics. However, logistics managers do not always have the expertise required in order to select the most appropriate IT system in relation to the characteristics of a given supply chain. This problem threatens to undermine the benefits offered by the concept of supply chain management (SCM) in conjunction with IT. Therefore, the purpose of this research was to identify the main IT systems used in SCM within the gas industry. Six strategic organizational variables: Integration, Warehousing Costs, Transportation Costs, Speed of Transportation, Competitiveness, and Interorganizational Coordination were used to analyze the impacts of IT investments on SCM in the industrial gas sector. The findings indicate that Integration, as a strategic organizational variable, undergoes the greatest impact with the use of IT, being followed by Competitiveness, Transportation Costs and Speed of Transportation.
\end{abstract}

\section{KEY WORDS}

Information Technology, supply chain management, strategic organizational variables. 


\section{INTRODUÇÃO}

Nas últimas décadas, o ambiente empresarial foi marcado por mudanças relevantes. A globalização tem obrigado as organizações a se preocupar, além dos seus custos, com aspectos como clientes, diferenciação de produtos, Tecnologia da Informação (TI), inovação e cadeia de suprimentos. Nesse sentido, as empresas procuram melhorar o nível de serviço e reduzir custos na tentativa de se diferenciar e aumentar a percepção de valor dos seus clientes. Para tanto, utilizam, em larga escala, a TI.

Haley e Krishnam (1995) identificam a Logística como a área empresarial que mais se beneficiou da automatização e da redução dos custos permitida pela TI. A TI é um recurso imprescindível para o sucesso de iniciativas de logística e Supply Chain Management (SCM). Assim, o uso da TI na SCM é um tema de destaque, que tem chamado atenção no mundo corporativo (WU et al., 2006).

\section{$\underline{E}$ crescente o número de empresas que investem em TI visando aumentar a eficiência}

\section{de suas cadeias de suprimentos.}

É crescente o número de empresas que investem em TI visando aumentar a agilidade e eficiência de suas cadeias de suprimentos. Aproximadamente 5,5 bilhões de dólares foram gastos em TI para SCM em 2003 (SEROPPIAN, 2004), sendo que a tendência é que estes investimentos aumentem ainda mais. Cook et al. (2002) relatam que, nos Estados Unidos, os investimentos em TI para SCM crescem a taxas anuais de $20 \%$. Entretanto, esta não é uma tendência restrita a países desenvolvidos. Os investimentos em TI para logística na América Latina devem aumentar 12,8\% em 2007 (BARBOSA, 2007). Apesar do papel relevante da TI na SCM, apenas investir em TI não é suficiente para garantir um maior desempenho das cadeias. Também são necessárias medidas de gestão que visem à integração da logística.

São diversas as TI disponíveis para a aplicação na logística. Contudo, percebe-se a existência de gaps substanciais de experiência e conhecimento entre os profissionais de TI e os responsáveis pelos processos logísticos. Muitas vezes, os profissionais de logística não têm conhecimento sobre o melhor sistema a adotar segundo as características de sua cadeia (GUNASEKARAN; NGAI, 2003). Se não forem eliminados, estes gaps impedirão a materialização das promessas trazidas pela combinação do conceito de SCM e TI. Assim, esta pesquisa procura listar as principais tecnologias de informação aplicadas na SCM, além de identificar as mais empregadas no setor de gases industriais.

Apesar da literatura apresentar diversos trabalhos sobre a adoção da TI na cadeia de suprimentos, ainda há poucos estudos empíricos sobre o impacto do uso da TI na SCM em relação às variáveis estratégicas organizacionais (GUNASEKARAN; NGAI, 2003). Byrd e Davidson (2003) salientam a falta de modelos que mensurem os impactos da TI na gestão das cadeias. Explorando esta oportunidade de pesquisa, Feldens (2005) desenvolveu um instrumento que, por meio da percepção dos executivos, avalia o impacto da TI na SCM. Utilizando o instrumento de Feldens (2005), esta pesquisa se propõe a analisar os impactos da TI na gestão da cadeia do setor de gases industriais por meio de seis variáveis estratégicas: Integração, Custos de Armazenagem, Custos de Movimentação, Velocidade e Competitividade e Coordenação Interorganizacional.

Inicialmente, analisa-se a integração entre a TI e a logística, sendo listados os principais sistemas de TI na SCM e o seu impacto nas variáveis estratégicas organizacionais. Posteriormente, são expostos os procedimentos metodológicos adotados para a realização da pesquisa. Em seguida, é feita uma contextualização do mercado estudado. Apresentam-se, então, as análises, individuais e comparativas, dos resultados dos estudos de caso múltiplos desenvolvidos nesta pesquisa. Enfim, são abordadas as conclusões e sugestões para novos trabalhos.

\section{A INTEGRAÇÃO ENTRE TECNOLOGIA DE INFORMAÇÃO E LOGÍSTICA}

A informação sempre foi um elemento importante para as operações logísticas, sem o qual nenhum aspecto da cadeia de suprimentos conseguiria proporcionar um alto nível de desempenho. Porém, o advento de novas tecnologias possibilitou a troca rápida e precisa de informações, permitindo melhor oferta de informações aos clientes, redução de estoques, minimização de incertezas em torno da demanda e aumento da flexibilidade.

A TI contribui para tornar a logística mais eficiente na geração de valor para as empresas, permitindo que as organizações colaborem de forma segura com os integrantes da cadeia de suprimentos, em qualquer lugar e a qualquer instante. Dias et al. (2003) enumeram os seguintes benefícios atingidos pelo uso da TI na SCM: (i) compartilhamento de informações instantâneas; (ii) compartilhamento de programas que aumentam a eficiência 
operacional; (iii) acompanhamento em tempo real, pelo consumidor, da carga; (iv) desenvolvimento de canais de venda globais; (v) redução dos estoques; e (vi) maior flexibilidade. Assim, o impacto da TI na SCM é um tema que desperta crescente interesse do mundo corporativo (WU et al., 2005).

As empresas norte-americanas são cada vez mais dependentes dos benefícios trazidos pela TI para aumentar a agilidade e eficiência das cadeias de suprimentos (WU et al., 2005). Tal importância é confirmada pelos altos investimentos em softwares para a SCM. Entretanto, os investimentos em TI não garantem impactos positivos diretos na operação das cadeias. Trata-se do Paradoxo da Produtividade, que não se aplica apenas aos investimentos em sistemas aplicados a SCM, mas também às demais áreas empresariais. Wu et al. (2005) posicionam-se sobre o paradoxo ao afirmar que os benefícios da TI são indiretos e difusos, sendo assim de difícil mensuração. A avaliação dos impactos da TI por meio da percepção de executivos, como é feito nesta pesquisa, é uma alternativa subjetiva para mensurar benefícios intangíveis.

\subsection{Sistemas de TI em Logística}

Em termos de TI existem diversas soluções disponíveis para a aplicação na logística. Patterson et al. (2003) apontam as principais tecnologias que têm sido utilizadas na área: (i) sistemas legados; (ii) código de barras; (iii) smartlabels; (iv) projeto assistido por computador - CAD (Computer Aided Design); ( $v$ ) inteligência empresarial - BI (Business Inteligence); (iv) intercâmbio eletrônico de dados EDI (Eletronic Data Interchange); (vii) rastreamento de frotas; (viii) sistema de automação do controle de qualidade - AQC (Automated Quality Control); (ix) sistema de execução da manufatura - MES (Manufacturing Execution System); $(x)$ sistema de gerenciamento de transportes TMS (Transportation Management System); (ix) sistema de gestão de armazéns - WMS (Warehouse Management System); (xii) sistema de gestão de relacionamento com clientes - CRM (Customer Relationship Management); (xiii) sistema de gestão de desenvolvimento de produtos - PDM (Product Development Management); (xiv) identificação por radiofreqüência - RF (Radio Frequency); ( $x v$ ) sistema de planejamento da cadeia de suprimentos - SCP (Supply Chain Planning); ( $x v i)$ sistema de previsão de demanda DFS (Demand Forecasting System); (xvii) sistema de informação baseado na Internet - WIS (Web-based Information System); (xviii) B2B e (xix) sistema integrado de gestão ERP (Enterprise Resource Management). A Tabela 1 apresenta a descrição dessas tecnologias e de sua aplicação na SCM.

\subsection{Impacto da TI nas variáveis estratégicas organizacionais}

São poucos os pesquisadores que estudam os impactos dos investimentos de TI na SCM (GUNASEKARAN; NGAI, 2003) e, em geral, as medidas de desempenho adotadas baseiam-se apenas em aspectos econômicos (Retorno sobre o Investimentos - ROI, Retorno sobre os Ativos - ROA, Retorno sobre Vendas - ROS). Assim, esta forma de observar os investimentos em TI tem sido criticada por desconsiderar aspectos relevantes para as organizações (BERGERON et al., 2001). Devido a essas críticas, é crescente a utilização da percepção dos executivos como forma de analisar o impacto e o valor da TI (TORKZADEH; DOLL, 1999; NEIROTTI; PAOLUCCI, 2007).

Feldens (2005) apresenta uma revisão da literatura sobre o assunto, além de propor um modelo de pesquisa para mensuração dos impactos da TI na gestão das cadeias, exposto na Figura 1. Como resultado de sua pesquisa, o autor destaca a identificação de seis variáveis impactadas pelo uso da TI na SCM, sendo elas: Integração, Custos de Armazenagem, Custos de Movimentação, Velocidade, Competitividade e Coordenação Interorganizacional. As variáveis são descritas a seguir (FELDENS, 2005).

- Integração: é a extensão da conexão entre as atividades da organização e de seus parceiros. Por meio da TI, as empresas conseguem simplificar seus processos decisórios, mantendo maior intercâmbio de informações entre os parceiros da cadeia e facilitando a integração das atividades de planejamento e controle da produção.

- Custos de Armazenamento e de Movimentação: $O$ custo logístico total se divide em: custos de estoque e armazenamento; de transporte e movimentação; e de instalações (NOVAES, 2004). O emprego da TI pode reduzir os custos de armazenamento e de movimentação da cadeia pelo melhor planejamento destas atividades e pela diminuição de processos administrativos com conseqüente redução de papéis, pessoal e estoque.

- Competitividade: $\mathrm{O}$ uso da TI viabiliza iniciativas que resultam em ganhos de vantagem competitiva para a cadeia, como: agilidade, velocidade de resposta às novas demandas do mercado, aumento da flexibilidade, atendimento personalizado, maior satisfação do cliente e atuação em diferentes mercados.

- Velocidade: A TI proporciona a agilização dos processamentos de informações e eliminação de atividades redundantes, aumentando assim a velocidade dos processos da cadeia.

- Coordenação interorganizacional: Trata-se do planejamento de ações integradas entre as organizações, tais como a formação de alianças entre os componentes da 
Tabela 1: Sistemas de TI Aplicados a SCM.

\begin{tabular}{|c|c|}
\hline Tecnologia & Descrição \\
\hline $\begin{array}{l}\text { Sistemas } \\
\text { legados }\end{array}$ & $\begin{array}{l}\text { Sistemas baseados em mainframe que funcionam em nível operacional em apenas um estágio. São construídos } \\
\text { como blocos independentes, o que dificulta a sua comunicação com outros sistemas. Foram os primeiros sistemas } \\
\text { utilizados na SCM. }\end{array}$ \\
\hline $\begin{array}{l}\text { Código } \\
\text { de barras }\end{array}$ & $\begin{array}{l}\text { Tecnologia de alocação de códigos legíveis por computador em itens, caixas e contêineres. Empregada para } \\
\text { melhorar a precisão da informação e velocidade de transmissão de dados, é utilizada na gestão de inventários, } \\
\text { depósitos, em supermercados etc. }\end{array}$ \\
\hline CAD & $\begin{array}{l}\text { Permite a realização de desenhos industriais na tela do computador que podem ser armazenados, manipulados } \\
\text { e atualizados eletronicamente. }\end{array}$ \\
\hline BI & $\begin{array}{l}\text { Conjunto de aplicações que organiza e estrutura os dados de transação de uma organização, facilitando a análise } \\
\text { de modo a beneficiar as operações e o suporte às suas decisões. }\end{array}$ \\
\hline EDI & $\begin{array}{l}\text { É a transferência eletrônica de dados entre parceiros de negócios. Os dados são estruturados segundo padrões } \\
\text { previamente acordados entre partes. Divide-se em duas categorias: o EDI tradicional, que utiliza serviços da rede } \\
\text { de valor agregado, e a WebEDI, com acesso de formulários pela internet. }\end{array}$ \\
\hline $\begin{array}{l}\text { Rastreamento } \\
\text { de frotas }\end{array}$ & $\begin{array}{l}\text { Pode ser baseado em transmissão via satélite ou pela telefonia celular para rastreamento e monitoramento de } \\
\text { veículos, sendo aplicados para controle de desempenho e segurança de transportes. Os dados gerados por esse } \\
\text { sistema alimentam o TMS e WMS. }\end{array}$ \\
\hline AQC & $\begin{array}{l}\text { Responsável pelo monitoramento dos processos de garantia da qualidade, de inspeção, especificações e calibração } \\
\text { dos instrumentos de medição. }\end{array}$ \\
\hline M.E.S. & $\begin{array}{l}\text { Sistemas de planejamento de utilização de recursos que visam otimizar e sincronizar a utilização dos mesmos. } \\
\text { Suportam o intercâmbio de informações entre o planejamento da produção e o controle do processo de produção } \\
\text { através do monitoramento e acompanhamento da matéria-prima, equipamento, pessoal, instruções e instalações } \\
\text { de produção. }\end{array}$ \\
\hline TMS & $\begin{array}{l}\text { Responsável pelo controle do transporte de cargas, determinando o modal, gerenciando a consolidação de fretes } \\
\text { e coordenando os esforços de transporte. }\end{array}$ \\
\hline WMS & $\begin{array}{l}\text { Otimiza as atividades operacionais (fluxo de materiais) e administrativas (fluxo de informações) no processo de } \\
\text { armazenagem, rastreando e controlando o movimento do inventário no depósito. Sua utilização está restrita a } \\
\text { decisões operacionais, tais como: definição de rotas de coleta, de endereçamento de produtos, etc. }\end{array}$ \\
\hline CRM & $\begin{array}{l}\text { Ferramenta capaz de unificar as informações sobre os clientes e de criar uma visão única, centralizando as } \\
\text { interações e antecipando as necessidades dos clientes. Proporciona ainda o controle de atividades promocionais } \\
\text { e seus impactos na demanda assim como o controle de atividades de garantia de produtos. }\end{array}$ \\
\hline PDM & $\begin{array}{l}\text { Gerencia as informações relacionadas aos produtos, servindo como uma ferramenta de integração que conecta } \\
\text { diferentes áreas de desenvolvimento de produtos. }\end{array}$ \\
\hline RF & $\begin{array}{l}\text { Facilita a comunição, disponibilizando informações essenciais sobre a situação dos produtos (BORWERSOX \& } \\
\text { CLOSS, 2001). Ferramenta de suporte que automatiza processos e melhora a gestão das operações, eliminando } \\
\text { falhas humanas. }\end{array}$ \\
\hline SCP & $\begin{array}{l}\text { Auxilia no planejamento, execução e mensuração dos processos, incluindo módulos de previsão de demanda, } \\
\text { planejamento de inventário e distribuição. }\end{array}$ \\
\hline DFS & $\begin{array}{l}\text { Utiliza métodos matemáticos que manipulam dados históricos e dados externos para previsão de demanda por } \\
\text { produtos e serviços. Em geral, integra outros sistemas, como ERP e SCP. }\end{array}$ \\
\hline WIS & $\begin{array}{l}\text { Facilita os processos internos e externos das empresas, integrando sistemas empresariais de informação. Na SCM, } \\
\text { os WIS mais presentes são o e-procurement e o e-market place, que são sistemas de automação de processos } \\
\text { de compras corporativas. }\end{array}$ \\
\hline B2B & $\begin{array}{l}\text { Mercados eletrônicos onde fornecedores e compradores interagem para conduzir transações. Trata-se de um } \\
\text { e-business, isto é, de relações entre empresas (HARRISON \& VAN HOECK, 2003) }\end{array}$ \\
\hline ERP & $\begin{array}{l}\text { Sistema unificado de informação que integra os departamentos e funções da empresa. Melhora o fluxo de } \\
\text { informações da cadeia em tal grau que se tornou um padrão de operação. }\end{array}$ \\
\hline
\end{tabular}


cadeia. Através da TI, pode-se atingir um nível mais elevado de coordenação entre os membros da cadeia, facilitando a troca de informações e o planejamento colaborativo.

Optou-se pelo uso do modelo conceitual de Feldens (2005) para o desenvolvimento desta pesquisa, devido à sua multidimensionalidade, ou seja, pelo conjunto de dimensões que o compõe e que foram validadas no contexto nacional. Outros elementos que suportam a utilização do modelo é que seus constructos e escala foram validados e confirmados por técnicas estatísticas multivariadas, baseados em equações estruturais. Trata-se, então, de um modelo robusto, cuja aplicabilidade em outras cadeias é recomendada pelo autor (FELDENS, 2005).

\section{METODOLOGIA}

Nesta seção são descritos os procedimentos metodológicos adotados para realização da pesquisa.

\subsection{Tipo de Pesquisa}

A presente pesquisa é de cunho qualitativo, sendo adotado o estudo de casos múltiplos como estratégia de investigação. Seu escopo consiste em identificar como as empresas do setor de gases industriais adotam sistemas de TI em suas cadeias de suprimento, além de analisar os impactos da TI na SCM deste setor. Assim, a pesquisa busca responder à seguinte questão: como os investimentos em TI impactam a gestão das cadeias de suprimento?

Optou-se pelo estudo comparativo de casos múltiplos porque esta técnica permite confrontar e comparar, por justaposição, um fenômeno em diferentes contextos (BENBASAT et al., 1987). Esta pesquisa é de caráter exploratório, dado que este é um tema pouco estudado. Assim, esta pesquisa proporciona uma visão geral sobre o tema em estudo, levantando questões e hipóteses para futuros estudos.

\subsection{Instrumento}

O instrumento utilizado baseou-se no desenvolvido e validado por Feldens (2005), cujo objetivo consiste em auxiliar no processo de avaliação do impacto da TI nas variáveis estratégicas organizacionais da SCM. Contudo, foi necessário adaptá-lo para o desenvolvimento do protocolo desta pesquisa. O instrumento é divido em duas partes, sendo a primeira formada por perguntas abertas que constituem um roteiro de entrevista semi-estruturado. A segunda parte consiste em um questionário sobre o nível de utilização da TI e seu grau de compartilhamento, sendo utilizada a escala Likert de cinco pontos para a mensuração. $\mathrm{O}$ roteiro foi submetido à avaliação de dois especialistas, um acadêmico da área de Sistemas da Informação e um executivo de SCM, que avaliaram a compreensão e relevância das questões, assegurando a validade de face e de conteúdo.

\subsection{Execução do Estudo de Caso}

Foram pesquisadas empresas de gases industriais. Esta

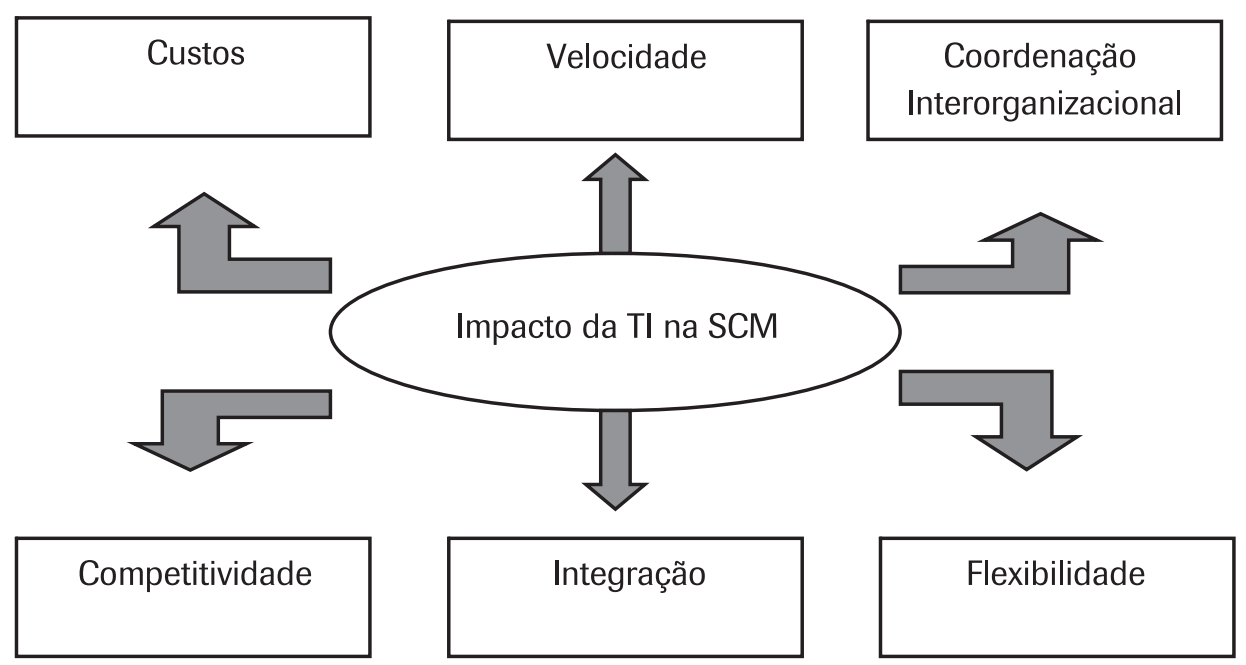

Figura 1. Modelo de Avaliação do Impacto da TI no SCM.

Fonte: Feldens (2005). 
escolha fundamenta-se no fato de que o setor tem uma cadeia de suprimentos desenvolvida, consistente e com altos investimentos em TI na gestão de SCM. O mercado brasileiro de gases industriais corresponde a um bilhão de dólares, sendo extremamente competitivo e dominado por poucas organizações (MELLO, 2003). Assim, foram selecionadas como unidades de análise para o estudo de caso três das principais empresas do setor e que correspondem a $80 \%$ do market share. Por questão de sigilo requisitado pelas empresas para o desenvolvimento da pesquisa, as mesmas não são identificadas.

\section{Ada fl na gestão das cadeias de suprimentos.}

A escolha por empresas do mesmo setor se justifica por facilitar a comparação entre os casos e corroborar para a validade externa do protocolo (OLIVEIRA et al., 2006). Para contribuir com a validade externa da pesquisa, foram escolhidas empresas consolidadas e entrevistados experientes, responsáveis pela SCM e com intenso relacionamento com o uso de TI, além da realização de estudos de casos múltiplos. A lógica adotada na seleção dos casos é a de replicação literal. Foram aplicados os mesmos procedimentos de pesquisa em todas as empresas analisadas, seguindo o mesmo protocolo de pesquisa.

A pesquisa foi realizada em julho de 2006. Inicialmente, foram feitos contatos telefônicos com as empresas selecionadas, sendo apresentados o tema e objetivos da pesquisa, além da forma como a organização deveria participar. Cada empresa indicou um funcionário a ser entrevistado, atendendo à exigência de que este trabalhasse na gestão da cadeia de suprimentos e que tivesse intenso relacionamento com o uso da TI. As entrevistas, com duração média de 2 horas, ocorreram nas organizações, sendo estas gravadas e transcritas pelos pesquisadores. Os questionários foram aplicados durante a entrevista, sendo preenchidos pelos próprios pesquisadores.

Para análise das entrevistas, realizou-se a análise de conteúdo, adotando-se como categorias as seis variáveis estratégicas do modelo de Feldens (2005). Nesta pesquisa, foi utilizada a análise temática, que consiste em descobrir "núcleos de sentido" que compõem a comunicação e cuja freqüência de aparição consiste em alguma coisa para o objetivo analítico escolhido (BARDIN, 1977). Esta análise é constituída por três fases: pré-análise; exploração do material; e tratamento e interpretação dos resultados obtidos. Para tanto, utilizou-se o software SPHINX.
A principal fonte de dados foram as entrevistas semiestruturadas e questionários. Porém, ressalta-se que, para se obter um maior conhecimento de cada empresa pesquisada, também foram investigados os websites das empresas, reportagens (PACHIONE, 2003; FAIRBANKS, 2006) e pesquisas (MELLO, 2003; MELLO et al., 2006) sobre o setor. Segundo Yin (2001), a pesquisa documental ajuda a evidenciar informações que foram obtidas por intermédio de outras fontes. Assim como a pesquisa documental, a observação direta nas empresas também ajuda na complementação das informações coletadas em um estudo de caso (TRIVIÑOS, 1987). Estas observações foram realizadas durante as entrevistas e visitas às organizações.

Com base nestas três fontes de dados, foi feita a triangulação das informações obtidas. A triangulação é um processo de múltiplas percepções, em que várias fontes de evidências são utilizadas para tornar as idéias mais claras, tendo em vista a repetição de observações e interpretações (YIN, 2001). A triangulação contribuiu para tornar o estudo de caso robusto, pois ajudou os investigadores na melhor compreensão do funcionamento do setor, das unidades de análise e da validade prática dos construtos selecionados na literatura de TI.

\section{ESTUDO DE CASO}

Nesta seção, é feita uma contextualização do mercado de gases. Apresenta-se também a análise dos resultados do estudo de casos múltiplos.

\subsection{Mercado de Gases Industriais}

Os gases estão presentes na área hospitalar, alimentícia, têxtil e de combustíveis. Esse mercado está relacionado aos níveis de desenvolvimento e produção industriais, havendo uma forte correlação entre a demanda e o Produto Interno Bruto (PIB). O setor apresenta taxas médias de crescimento que variam de 1,5 a 2 vezes o aumento do PIB. Em 2003, o mercado mundial de gases industriais correspondeu a US\$ 34,5 bilhões (MELLO, 2003).

O setor de gás industrial opera em um mercado darwiniano, no qual os princípios da seleção natural levam à sobrevivência apenas das empresas mais ajustadas às necessidades do cliente (PACHIONE, 2003). Segundo Fairbanks (2006), o mercado brasileiro de gases verificou nos últimos anos acirramento da concorrência, estimulada pelo aparecimento de novos players e pela investigação oficial sobre práticas de cartel. Ainda, as negociações com clientes globais se tornaram mais difíceis. As empresas internacionais pressionam 
para pagar o mesmo preço pelo produto em todo o mundo, desconsiderando as diferenças do Brasil em custo de eletricidade e carga tributária.

Em 2006, o mercado de gases no Brasil foi equivalente a US\$ 1,2 bilhão, representando dois terços do mercado sulamericano (FAIRBANKS, 2006). O setor é dominado pela White Martins, subsidiária da empresa americana Praxair, seguido pela AGA, Air Liquide e Air Products.

O portfolio de produtos dessas indústrias inclui gases atmosféricos, de processo, especiais, medicinais e equipamentos para aplicação, transporte e armazenamento de gases. Neste setor, não existe uma diferenciação significativa entre os produtos. Assim, para que determinada empresa retire de seus produtos o conceito de commodity, esta deve agregar valor através de serviços. Isto requer uma rede de distribuição eficiente que permita um pronto atendimento ao cliente, pois alguns setores da cadeia produtiva não podem ficar sem produto sob pena de perdas de vidas (hospitais) ou perda total da produção (siderurgia).

Os produtos da indústria de gases industriais podem ser transportados por caminhões, caminhões-tanque ou gasodutos. A comercialização de gases industriais é efetuada por cilindros, tanques ou plantas on-site, localizadas na área do cliente. Esta prática tem se destacado no mercado, uma vez que são os projetos dos clientes que motivam a expansão do parque produtivo (FAIRBANKS, 2006).

\subsection{Resultados dos Estudos de Caso}

Apresentam-se a seguir os resultados dos três estudos de caso realizados. As unidades de análise são três das principais empresas do setor, de modo que são organizações de capital internacional, que empregam de 18 a 31 mil funcionários. No Brasil, estas empresas apresentam faturamentos entre 100 e 700 milhões de dólares, conforme informações contidas nos seus websites. Tais características não são detalhadas para cada unidade de análise para não caracterizar as empresas em questão. Os respondentes indicados pelas empresas foram os gerentes de logística, responsáveis pela SCM, que possuem forte integração com a TI. Dos três respondentes, dois são graduados em Engenharia e um em Administração de Empresas, sendo que atuam nas empresas estudadas entre dois e 25 anos.

\subsection{Caso Gases 1}

A empresa Gases 1 faz uso de modernas técnicas e ferramentas de gestão, destacando-se: Certificação ISO 9001:2000, Balanced Score Card (BSC), Benchmarking, Seis Sigma, Gerência de projeto (PMI), Material Requirements Planning (MRP), Total Quality Management (TQM), Out- sourcing (3PL), Vendor Managed Inventory (VMI) e Avaliação Estratégica de Fornecedores.

A empresa apresenta uma visão sistêmica do conceito de logística, considerando a importância dos serviços logísticos para a diferenciação de seus produtos. Segundo o gerente de logística, os custos logísticos representam uma alta porcentagem do custo total do produto, de forma que uma melhoria no sistema logístico pode implicar em aumentos consideráveis no faturamento da empresa. Assim, a organização investe constantemente em ferramentas para otimizar a sua cadeia.

A Gases 1 dispõe de centrais de atendimento pós-venda e uma malha de distribuição que cobre todo território nacional. Em relação ao processo de distribuição, existem dois tipos de clientes: por abastecimento automático ou por pedido. Os clientes atendidos mediante pedido são abastecidos segundo as freqüências que julgam vantajosas. Para melhorar $o$ atendimento destes clientes, a empresa possui uma Central de Atendimento ao Consumidor, através da qual podem ser realizadas solicitações via webEDI. Os clientes abastecidos diretamente têm seu processo gerenciado pela empresa, de modo que não precisam se preocupar com o nível de gás dos tanques, pois este será reposto quando atingir um ponto predeterminado. Para manter este controle, a Gases 1 utiliza o Sistema de Monitoramento Remoto de Tanques.

\section{$\Lambda$ avaliação dos impactos da TI por meio da percepção de executivos é uma alternativa subjetiva para mensurar benefícios intangíveis.}

A organização integra a cadeia de suprimentos através de um sistema de gerenciamento que utiliza tecnologias como: ERP, CRM, CAD, SCP, WMS, MES, BI e Sistemas de Código de Barra. Como possui frota própria, a empresa também utiliza TMS e Sistemas de Rastreamento de Frota Geo-codificado. Não são empregados os seguintes sistemas: PDM, AQC, RF e WIS. Porém, a empresa tem planos de adotá-los. Para o gerente de logística, os sistemas mais importantes na SCM são: ERP, CRM, AQC, CAD, SCP, WMS e MES. Os sistemas de TI adotados pela empresa têm alto grau de compartilhamento com os parceiros da cadeia - clientes e fornecedores. Entretanto, o Sistema de Códigos de Barra e os Sistemas de Rastreamento de Frota são compartilhados apenas com os clientes.

O gerente de logística afirma que a TI tem alto impacto sobre o desempenho da cadeia de suprimentos da empresa, em especial nas atividades de transporte, distribuição, ad- 
ministração de estoque e compras. Para ele, a implantação de um sistema de TI é um processo trabalhoso que requer o redesenho das estruturas organizacionais (ampliação e complexidade). Porém, o gerente indica que este é um processo vantajoso, pois a utilização da TI proporciona maior qualidade nos produtos e serviços. Dentre as principais vantagens competitivas, cita a redução de custos, o melhor roteamento de distribuição, o melhor planejamento da produção e o balanceamento entre demanda e produção.

O executivo, considerando as variáveis selecionadas para o estudo, apontou os seguintes impactos do uso da TI na gestão da cadeia de suprimentos:

- Os sistemas de TI permitem melhor planejamento e gestão da cadeia de suprimentos, o que possibilita a redução do custo de administração de logística, a redução nos níveis de estoque e, conseqüentemente, a redução no custo de armazenamento.

- Por meio de tecnologias como o TMS, há o gerenciamento da consolidação de fretes e otimização da frota, possibilitando a redução dos custos de movimentação.

- Existe o aumento da velocidade, por meio da redução do tempo de disponibilização de mercadorias junto ao parceiro e ao aumento da precisão de entregas.

- A implementação coordenada de sistemas de TI possibilita a coordenação e planejamento das atividades logísticas em conjunto com parceiros da cadeia de suprimentos. Fica evidente o aumento do comprometimento e da confiança nas relações com os clientes, uma vez que é crescente a prática do VMI por parte da empresa.

- O uso da TI viabiliza a diferenciação os produtos da empresa em relação aos concorrentes, principalmente por se tratar de uma commodity. Isto possibilita aumento da competitividade.

- Impacto forte sobre a integração, uma vez que, por meio da TI, a empresa consegue manter maior nível de comunicação entre os parceiros da cadeia, construindo uma rede de distribuição integrada, presente em todo território nacional.

\subsubsection{Caso Gases 2}

A empresa Gases 2 conta com uma ampla cadeia de produção, vendas e distribuição de modo a garantir o abastecimento de clientes em todo território nacional. A companhia desenvolve um programa de qualidade total segundo as normas ISO 9000, além de fazer uso de técnicas e ferramentas gerenciais como: o BSC, Análise de valor, Benchmarking, Seis Sigma, TQM, Outsourcing e Avaliação Estratégica de Fornecedores.

A organização está ciente da importância da TI para dar mais agilidade aos negócios corporativos. Visando otimizar suas atividades e melhorar o relacionamento com os clien- tes, a Gases 2 tem realizado altos investimentos em infraestrutura de TI e telecomunicações. A companhia selecionou um provedor de telecomunicações para a América Latina e migrou sua infra-estrutura de redes baseada em protocolo IP. O gerente de TI afirma que a meta inicial da companhia é economizar R \$ 150 mil com o projeto, além de ganhar mais rapidez e segurança no acesso às informações. O executivo "espera alcançar maior eficiência na utilização de diversas aplicações da TI, tal como o gerenciamento do relacionamento com o cliente (CRM). Com a rede IP corporativa, a empresa aumentará o nível de recepção de pedidos, emissão de notas e contas a receber, atendendo de forma mais eficiente fornecedores e clientes."

Dentre os sistemas de TI aplicados a SCM que a empresa utiliza, destacam-se: CRM, CAD, WMS, TMS, WIS e Sistemas de Rastreamento de Frota. Está em estudo a implantação do ERP na organização. O coordenador de Supply Chain da empresa acredita que esse sistema, junto ao CRM, CAD e WIS, são os que mais contribuem para a eficiência da cadeia, uma vez que promovem maior integração e controle através de análises estatísticas. Atualmente, não existe um grande grau de compartilhamento dos sistemas de TI em toda a cadeia. Apenas o CRM e o WIS são altamente compartilhados com clientes e fornecedores. O CAD tem um baixo grau de compartilhamento com os clientes, enquanto o WMS e o sistema de rastreamento apresentam médio grau de compartilhamento com os fornecedores.

Segundo o coordenador de Supply Chain, a TI aplicada a SCM resulta em vantagens competitivas para a empresa, tais como: redução de custos, maior eficiência no desenvolvimento do trabalho, maior controle e colaboração no desenvolvimento de estratégias. Para o executivo, as principais atividades logísticas apoiadas pela TI são aquelas relacionadas ao setor de Compras. As atividades de transporte, administração de estoques, processamento de pedidos e armazenagem também são apoiadas pela TI, porém com menor impacto. As atividades de manuseio de materiais e embalagem são consideradas pelo coordenador como atividades que têm pouca colaboração da TI.

Sobre os impactos do uso da TI na gestão das cadeias de suprimentos, o executivo citou os seguintes impactos nas variáveis selecionadas para o estudo:

- Redução do custo de administração de logística e custo de armazenamento maiores que a redução nos custos de movimentação. Menores custos de armazenamento são obtidos por meio da redução nos níveis de estoque.

- Existe pouco aumento da velocidade por meio da redução do tempo de disponibilização de mercadorias junto ao parceiro. No entanto, há maior confiabilidade pelo aumento da precisão de entregas. 
- A implantação coordenada de sistemas de TI possibilita a coordenação e planejamento das atividades logísticas em conjunto com parceiros da cadeia de suprimentos. Em menor grau, também colabora para o aumento do comprometimento e da confiança nas relações com os clientes e fornecedores.

- O uso da TI pouco colabora para a diferenciação dos produtos da empresa em relação aos concorrentes. $\mathrm{Na}$ verdade, os sistemas de TI ajudam na melhor negociação com os parceiros, o que possibilita aumento da competitividade.

- Por meio da TI, a empresa mantém maior comunicação entre os parceiros da cadeia, construindo uma rede de distribuição integrada. Isto corrobora para maior integração.

\subsubsection{Caso Gases 3}

A empresa Gases 3 destaca a preocupação em aprimorar a qualidade dos produtos, serviços e o valor agregado aos clientes como sua principal estratégia. No intuito de assegurar este aprimoramento, a organização adota a ISO 9000 como modelo. Ainda, a companhia faz uso de técnicas gerenciais como: o BSC, Benchmarking, Melhoria Contínua, Gerência de projeto e TQM.

A empresa se preocupa em oferecer serviço diferenciado a cada tipo de cliente. Para usuários de baixo a médio volume, são fornecidos gases em cilindros por meio de uma rede de distribuição capaz de atender a todo o país. Para usuários de médio e grande volume, os produtos são fornecidos a granel, transportados pela frota própria da empresa, ou instala-se uma planta on-site. A organização possui um sistema de fornecimento flexível, que se adapta à necessidade do cliente. Ainda, o fornecimento de gases é complementado por uma linha de serviços que inclui: consultoria aos processos do cliente, instalação e manutenção de equipamentos de gases, além de informações de segurança e treinamento.

Os sistemas de TI aplicados pela empresa na gestão da cadeia são: ERP, CAD, Sistemas de Rastreamento de Frota, WIS e EDI. O gerente de Supply Chain da companhia também destaca o sistema de monitoramento via Internet implantado pela empresa em 2003, através do qual foi obtida uma redução de $10 \%$ nos custos com frete, além de maior segurança no monitoramento dos tanques. O sistema de telemetria foi terceirizado, sendo o pagamento efetuado através de aluguel mensal, não requerendo investimentos em softwares e equipamentos. Através deste sistema, monitora-se instantaneamente o nível de estoque e consumo específico do cliente.

A empresa também planeja adotar em sua cadeia de supri- mentos o AQC, o SCP e o TMS. Como a companhia possui frota própria, a adoção desta tecnologia contribuirá para a gestão dos transportes e para o desempenho das atividades de distribuição.

Para o gerente de Supply Chain, os sistemas mais importantes para a cadeia são: ERP, SCP, WMS, TMS, RF, WIS, Sistema de Código de Barra, WIS e o Sistema de Telemetria. Contudo, o executivo aponta que o planejamento da implantação de TI não é coordenado com os demais membros da cadeia. Há pouco o compartilhamento da TI na cadeia, uma vez que a maioria dos sistemas da empresa é incompatível aos sistemas dos clientes e fornecedores. O único sistema compartilhado entre a empresa Gases 3 e seus fornecedores é o Sistema de Rastreamento de Frota Geo-codificado. Em relação aos clientes, há um baixo grau de compartilhamento do CAD, TMS e WIS.

\section{/ariáveis impactadas pelo uso da TI na SCM: Integração, Custos de Armazenagem, Custos de Movimentação, Velocidade, Competitividade e Coordenação Interorganizacional.}

O gerente de Supply Chain considera que a implementação da TI tem um alto impacto no desempenho da cadeia, especialmente no desempenho das atividades relacionadas ao transporte e distribuição, ao processamento de pedidos, à administração de estoques e a compras. Para o executivo, a TI tem pouco apoio nas atividades de armazenagem, manuseio de materiais e embalagem. Dentre as conseqüências da utilização da TI na empresa, o gerente destaca: (i) Reengenharia de Processos; (ii) Pensamento sistêmico; e (iii) Redesenho das estruturas organizacionais. Entretanto, o executivo não considera que a aplicação de TI à gestão da cadeia de suprimentos resulta em vantagem competitiva para a empresa, uma vez que os benefícios são de caráter operacional, melhorando o desempenho de uma atividade de apoio da empresa.

Segundo os impactos do uso da TI na SCM, o executivo destacou os seguintes impactos nas variáveis selecionadas para o estudo:

- Maior impacto na redução dos custos de movimentação do que na redução dos custos de armazenamento.

- Há redução do tempo de disponibilização de mercadorias junto ao parceiro e aumento da precisão de entregas, o que colabora para o aumento da velocidade.

- Evidencia o baixo impacto da implantação de TI no comprometimento das relações da cadeia, ressaltando 
haver maior colaboração para o aumento da confiança e da coordenação. Destaca como baixo o impacto da TI à variável coordenação interorganizacional.

- O uso da TI ajuda a empresa a fazer negócios de uma melhor forma com os parceiros da cadeia e na diferenciação dos produtos da empresa em relação aos concorrentes. Isto possibilita aumento da competitividade.

- Impacto forte sobre a integração, uma vez que a TI permite à empresa aumentar o nível de comunicação e de integração entre os parceiros da cadeia, construindo uma rede de distribuição integrada, presente em todo território nacional.

\subsubsection{Análise Comparativa dos Resultados}

A Figura 2 apresenta os resultados da análise de freqüência de utilização das tecnologias selecionadas para a pesquisa nas empresas caso. Além das tecnologias mais utilizadas, buscou-se levantar aquelas cujas implantações estão em fase de planejamento, visando identificar as tecnologias comuns às indústrias de gases industriais, bem como as tendências tecnológicas no setor.

Verifica-se a ampla utilização do CAD e de sistemas de rastreamento de frotas geo-codificado em todas as empresas. O ERP e o WIS são utilizados por dois terços das empresas analisadas, estando em fase de planejamento nas demais. $\mathrm{O}$ CRM, o WMS, o TMS e o EDI também apresentam alta taxa de utilização. $\mathrm{O}$ amplo uso do CAD já era esperado, pois no setor de gases industriais as informações geométricas sobre os produtos devem ser trocadas entre os componentes da cadeia. Os sistemas de rastreamento de frotas e o TMS são tecnologias com alto grau de utilização, pois todas as indús- trias analisadas possuem frotas próprias. O ERP é um padrão de operação e o EDI é o padrão de intercâmbio de informação das cadeias de suprimento. O WIS é uma tecnologia em ampla expansão, enquanto o CRM se apresenta como uma tendência entre diversas empresas. A adoção do WMS justifica-se por ser uma ferramenta que otimiza atividades operacionais e administrativas.

As tecnologias que apareceram com baixa utilização são o SCP, MES, código de barras, SCP e BI. Não são adotados por nenhuma empresa o AQC e a identificação por radiofreqüência, porém uma das organizações analisadas planeja suas implantações. Também foram identificadas as tecnologias consideradas mais importantes pelos executivos entrevistados, conforme exposto na Figura 3.

Segundo os executivos de Supply Chain, o sistema mais relevante é o ERP, seguido pelo CRM, CAD, SCP, WMS e WIS. Esperava-se que as tecnologias consideradas como mais importantes seriam aquelas de maior freqüência de utilização ou que estivessem em fase de planejamento de adoção. De fato, o ERP, o CAD e o WIS têm 100\% de adoção ou de planejamento, sendo seguidos pelo WMS e CRM que são utilizados por $66,7 \%$ das organizações analisadas. Apesar de ser considerado relevante pelos entrevistados, o SCP tem baixa utilização e não se apresenta uma tendência para os próximos anos. O SCP é importante por integrar diversas tarefas de gestão da cadeia de suprimentos, sendo de tal forma curiosa sua baixa adoção no setor de gases industriais. Feldens (2005) constatou que a implantação desta tecnologia era planejada pela maioria das empresas do setor metalmecânico. Verifica-se, então, uma oportunidade de melhoria para as organizações analisadas.

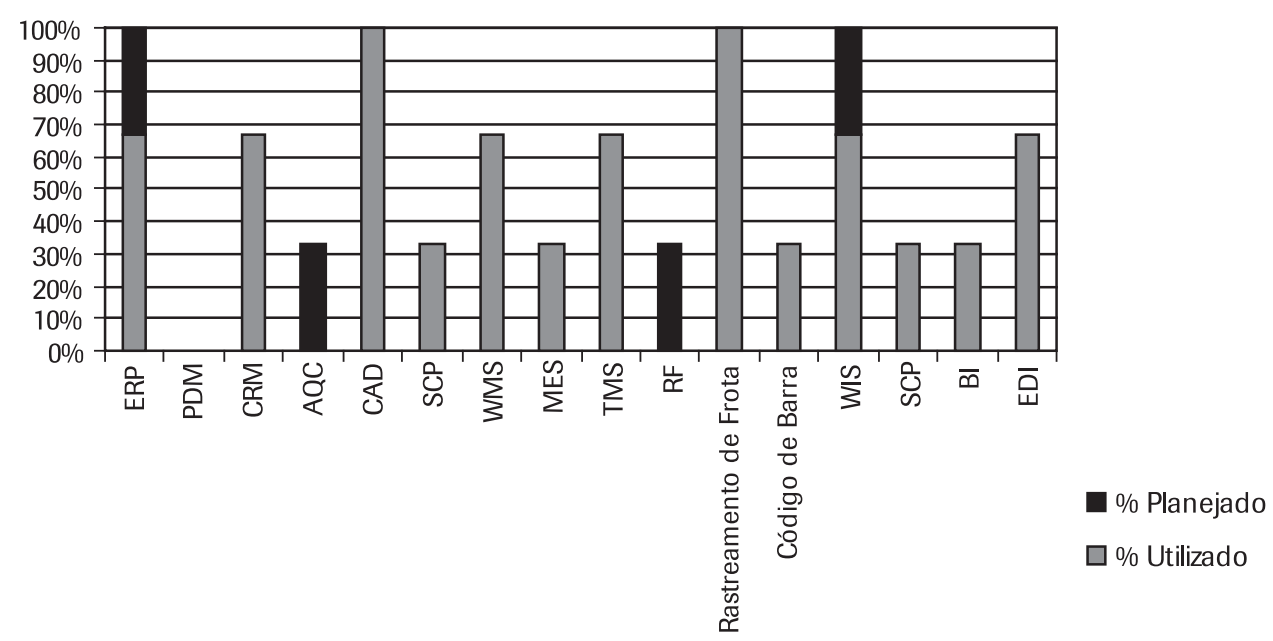

Figura 2: Utilização das Tecnologias. 
Apesar dos entrevistados afirmarem que a implementação de TI tem um alto impacto no desempenho da cadeia de suprimentos de suas empresas, estes variaram muito em suas opiniões sobre quais atividades logísticas têm seu desempenho mais afetado. A Tabela 2 apresenta os pesos dados pelos executivos quando solicitados a indicarem, em uma escala de 1 a 5, em que medida a TI apóia o processo de gestão da cadeia de suprimentos nas atividades logísticas. Destaca-se que "Transporte e Distribuição" e "Compras" foram identificadas pelas maiores empresas do setor como as atividades com maior impacto da TI.

Os executivos das empresas Gases 1 e 2 consideram que a TI aplicada a SCM resulta em vantagens competitivas para empresa, tais como redução de custos e eficiência no planejamento e desenvolvimento das atividades logísticas. O gerente da empresa Gases 1 também destaca o planejamento da produção e o balanceamento entre a demanda e a produção. Entretanto, o executivo da empresa Gases 3 acredita que a aplicação da TI a SCM não resulta em vantagem competitiva, trazendo apenas benefícios de caráter operacional para a logística, que desempenha atividades de apoio. Tais posturas refletem a cultura organizacional em relação à TI e à logística: a organização que não considera a aplicação da TI à SCM como estratégica é a que tem menor taxa de adoção de TI e menor compartilhamento dos sistemas entre parceiros da cadeia.

A empresa Gases 1 apresenta maior taxa de adoção de TI e de compartilhamento dos sistemas à medida que considera a integração da SCM como estratégica. O gerente de Supply Chain desta organização destacou o papel da TI no desempenho da cadeia, além de ter atribuído os maiores pesos aos impactos da TI nas variáveis estratégicas organizacionais.

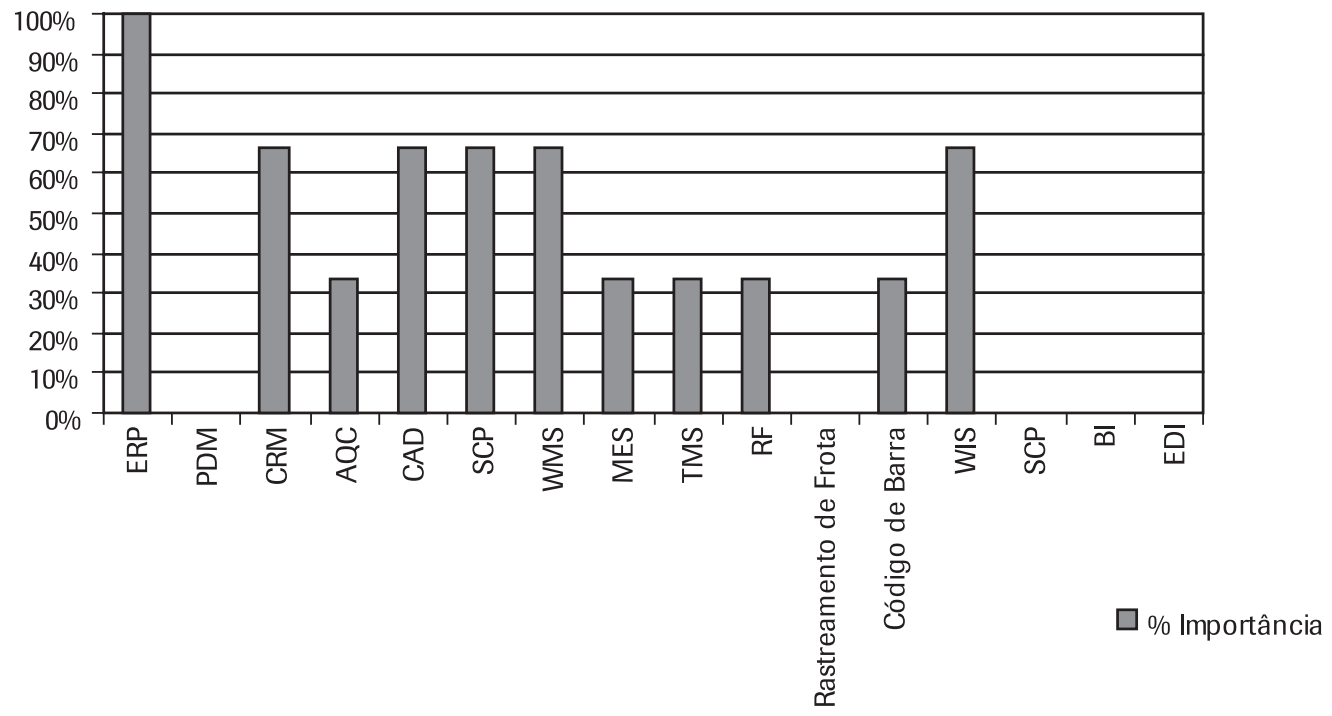

Figura 3: Importância da Tecnologias para Executivos de Supply Chain.

Tabela 2: Atividades Logísticas afetadas pela TI.

\begin{tabular}{cccc}
\hline Atividade & \multicolumn{3}{c}{ Caso } \\
\cline { 2 - 4 } & Empresa 1 & Empresa 2 & Empresa 3 \\
\hline Transporte e distribuição & 5 & 3 & 5 \\
Administração de estoques & 5 & 3 & 4 \\
Compras & 5 & 5 & 3 \\
Processamentos de Pedidos & 4 & 3 & 5 \\
Armazenagem & 4 & 3 & 2 \\
Manuseio de materiais & 4 & 1 & 2 \\
Embalagem & 4 & 1 & 2 \\
\hline
\end{tabular}


Estas variáveis foram operacionalizadas em uma escala de intensidade tipo Likert de 5 pontos, sendo os resultados apresentados na Tabela 3. A empresa Gases 2 também atribuiu altos pesos às variáveis organizacionais, além de apresentar uma alta taxa de utilização de TI. mais jovem que os demais entrevistados. Para possibilitar a comparação da percepção entre os grupos de respondentes deveria ser realizada uma pesquisa survey com amostra representativa para que sejam obtidos resultados estatísticos significativos.

\section{$\Delta \mathrm{s}$ indústrias de gases investem para melhorar Ao desempenho de sua cadeia, utilizando em larga escala a tecnologia da informação.}

Também foram levantadas as principais técnicas e ferramentas gerenciais adotadas pelas empresas de gases industriais na SCM, como apresenta a Figura 4. São ferramentas comuns a todas as empresas: (i) Certificação ISO 9001:2000; (ii) Balanced Score Card; (iii) Benchmarking; e (iv) Gestão da Qualidade Total. Duas destas ferramentas relacionam-

Segundo a percepção dos executivos, a Integração é a variável estratégica organizacional que sofre maior impacto pelo uso da TI. Este resultado corrobora com a pesquisa desenvolvida por Feldens (2005), onde é ressaltado o ganho de integração trazido pelo emprego de TI na SCM. O autor salienta que o aumento da integração é resultante do maior intercâmbio de informações entre os parceiros da cadeia e da maior integração de atividades de planejamento e controle dos processos de produção. Também há concordância na opinião dos entrevistados em relação ao impacto da TI sobre as variáveis Competitividade, Custo de Movimentação e Velocidade.

Nota-se discrepância nas percepções relativas ao Custo de Armazenamento e à Coordenação Interorganizacional. Os respondentes da empresa Gases 1 e 2 consideram a Coordenação interorganizacional como a segunda variável que recebe maior impacto da TI. Entretanto, o executivo da empresa Gases 3 a considera como sendo pouco influenciada pela TI. Além de diferenças na cultura organizacional, a percepção pode ser influenciada pelo perfil dos respondentes. Os executivos das empresas Gases 1 e 2 são os gerentes de SCM, sendo ambos engenheiros com mais de 20 anos de experiência. O respondente da empresa Gases 3 é administrador de empresas e coordenador de Supply Chain, sendo se à qualidade, ressaltando que a preocupação com qualidade dos produtos, serviços e o valor agregado aos clientes é uma estratégia comum no setor.

Ferramentas relacionadas à Produção Enxuta (Just in Time) e ao Custeio Baseado em Atividades ( $\mathrm{ABC}$ ) não são adotadas por nenhuma das empresas analisadas. O custeio $\mathrm{ABC}$ é uma forma de análise de processos empresariais que permite avaliar a eficiência das atividades, identificando a composição dos custos. O gerenciamento da cadeia de suprimentos pressupõe a visão integrada de custos, considerando conjuntamente todos os componentes da cadeia. Assim, o custeio ABC tem grande aplicação na SCM. Por meio deste método, as indústrias de gases industriais poderiam aumentar a eficiência das atividades que adicionam valor à cadeia, encontrando as raízes dos problemas. Práticas just-in-time também costumam ter ampla utilização em outros setores, pois estas ferramentas promovem a redução do lead-time da cadeia, o melhoramento do nível de serviço e redução de estoques. Assim, seria interessante a adoção destas ferramentas na cadeia de suprimentos de gases industriais.

Constatou-se, ainda, que as indústrias de gases industriais pouco utilizam sistemas VMI. A implantação, por parte das empresas estudadas, do conceito de Estoque Gerenciado pelo Fornecedor (VMI) traria maior eficiência na gestão do

Tabela 3: Impactos da TI às Variáveis Estratégicas Organizacionais.

\begin{tabular}{cccc}
\hline Tecnologia & \multicolumn{3}{c}{ Caso } \\
\cline { 2 - 4 } & Empresa 1 & Empresa 2 & Empresa 3 \\
\hline Integração & 5 & 4,67 & 4,67 \\
Custo de armazenamento & 4,33 & 3,67 & 2 \\
Coordenação Interorganizacional & 4,33 & 4,33 & 2,67 \\
Custo de Movimentação & 4 & 3 & 4 \\
Velocidade & 4 & 4 & 3,5 \\
Competitividade & 3,67 & 3,33 & 3,25 \\
\hline
\end{tabular}


estoque de gases, um controle mais apurado do processo logístico e redução nos custos da cadeia. Dessa forma, as empresas melhorariam sua produtividade e competitividade, além de oferecer um melhor produto ao cliente.

Em suma, as empresas analisadas estão conscientes sobre a importância da logística para diferenciar seus serviços, conquistar mercado e reduzir seus custos. O produto oferecido neste setor é uma commodity, de modo que os serviços logísticos têm um papel fundamental para sua diferenciação. A SCM é, então, uma questão estratégica para as empresas de gases industriais. Assim, a adoção de sistemas de TI é um ponto-chave para o sucesso das organizações, contribuindo de forma essencial para o bom desempenho das atividades logísticas. Contudo, as empresas deveriam ter maior preocupação em integrar a implantação da TI com os demais membros da cadeia, visando aumentar a coordenação e integração da cadeia de suprimentos.

\section{CONSIDERAÇÕES FINAIS}

Neste artigo, examinou-se a integração entre a TI e a logística, apresentado-se uma breve descrição dos principais sistemas de TI na SCM e o seu impacto nas variáveis estratégicas organizacionais. Em seguida são abordados os procedimentos metodológicos para a realização da pesquisa. Apresenta-se, então, a descrição das unidades de análise e os resultados da pesquisa, por meio de discussões e propostas de melhoria.
Esta pesquisa se propõe a analisar os impactos da TI na gestão da cadeia do setor de gases industriais por meio de seis variáveis estratégicas: Integração, Custos de Armazenagem, Custos de Movimentação, Velocidade, Competitividade e Coordenação Interorganizacional. Para tanto, desenvolveuse uma pesquisa de estudo de casos múltiplos, baseando-se no instrumento de mensuração dos impactos da TI na SCM proposto por Feldens (2005). Por meio da percepção dos executivos, buscou-se mensurar os benefícios intangíveis da TI na gestão da cadeia de suprimentos. Como limitações desta pesquisa destacam-se: (1) o desenvolvimento da pesquisa ter ocorrido apenas no setor de gases industriais e (2) a realização da amostra de respondentes por conveniência.

O artigo apresentou um estudo de casos múltiplos sobre a cadeia de suprimentos do setor de gases industriais, identificando as principais tecnologias de informação empregadas. Procurou-se levantar as tendências tecnológicas do setor, bem como identificar as principais práticas e ferramentas gerenciais aplicadas à gestão da cadeia. Foram pesquisadas três das principais indústrias de gases. Esta escolha fundamentase no fato de que o setor tem uma cadeia de suprimentos desenvolvida e consistente e que as atividades logísticas têm um papel fundamental no setor. Cientes da importância da logística, as indústrias de gases investem para melhorar o desempenho de sua cadeia de suprimentos. Para tanto, utilizam em larga escala a TI.

Segundos os executivos entrevistados, a implementação de TI tem um alto impacto no desempenho da cadeia de suprimentos de suas empresas. "Distribuição e Transporte"

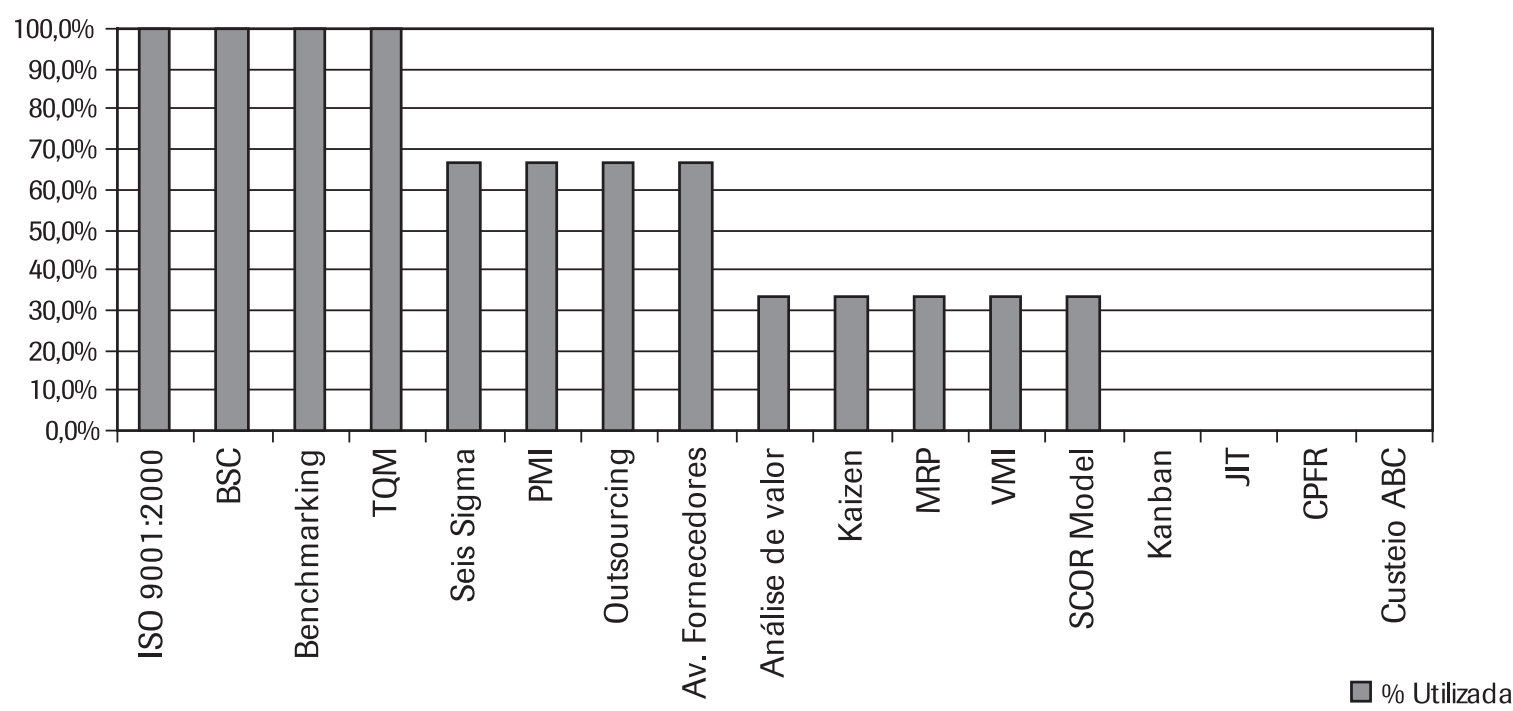

Figura 4: Utilização de Ferramentas Gerenciais na SCM. 
e "Compras" foram as atividades identificadas pelas maiores empresas do setor como as de maior impacto da TI.

A percepção dos executivos do setor de gases industriais aponta a Integração como a variável estratégica organizacional que sofre maior impacto pelo uso da TI, sendo seguida pela Velocidade, o Custo de Movimentação, Custo de Armazenamento, Coordenação Interorganizacional e Competitividade. Esses resultados se assemelham aos obtidos por Feldens (2005) ao aplicar o mesmo instrumento de pesquisa no setor metalmecânico. Os resultados encontrados por Feldens (2005) também apontam a Integração e a Velocidade como as variáveis com maiores níveis de impacto resultantes do uso da TI, bem como Coordenação Interorganizacional e Competitividade como as variáveis menos impactadas. A diferença entre os resultados se deu na ordem entre Custos de Armazenagem e Custos de Movimentação. Este fato, provavelmente, se deve à diferença das matrizes de custos logística das duas cadeias dada a importância do custo de movimentação no setor de gases industriais. A movimentação e o transporte representam a maior parcela do custo logístico da cadeia de gases industriais, sendo ainda que, depois do custo energético, a logística é o fator mais deter- minante na composição do custo do produto (MELLO \& BANDEIRA, 2006).

Salienta-se que examinar o impacto da TI em uma determinada área empresarial, tal como a cadeia de suprimentos, auxilia na compreensão do impacto da TI no desempenho da organização. Por meio da pesquisa realizada, fica clara a importância da TI para o sucesso de iniciativas de Logística e SCM. A TI contribui para tornar a logística mais eficiente e efetiva na geração de valor para as organizações. Contudo, muitas empresas não têm conhecimento sobre o melhor tipo de sistema de TI que deve implantar segundo as características de sua cadeia. Por isto, defende-se a ampliação da discussão sobre estes tópicos, de modo a facilitar a materialização das promessas trazidas pela SCM. Gunasekaran e Ngai (2003) enfatizam a existência de uma lacuna na literatura sobre os impactos da TI na SCM sobre as variáveis estratégicas organizacionais. Evidencia-se, então, a necessidade do desenvolvimento de novas pesquisas sobre o tema. Como sugestão de novos trabalhos, pode-se citar o estabelecimento de métricas comuns para a mensuração do impacto e da adequabilidade da aplicação das diferentes tecnologias da informação na cadeia de suprimentos.

\section{Artigo recebido em 14/05/2007 Aprovado para publicação em 04/03/2008}

\section{REFERÊNCIAS}

BARBOSA, A. Investimentos em TI aumentarão 12,8\% na América Latina. Disponível em $<$ http://www.estadao.com.br>. Acesso em 25 jan. 2007.

BARDIN, L. Análise de conteúdo. Lisboa: Edições 70, 1977.

BENBASAT, I.; GOLDSTEIN, D.; MEAD, M. The case research strategy in studies on information systems. In: MIS Quarterly, september, p. 368-386, 1987.

BERGERON, F.; RAYMOND, L.; RIVARD, S. Fit in strategic information technology management research: an empirical comparison of perspectives. In: Omega, n. 29, p.12-142, 2001.
BOWERSOX, D. \& CLOSS, D. Logística empresarial. São Paulo: Atlas, 2001.

BYRD, T. \& DAVIDSON, N. Examining possible antecedents of IT impact on the supply chain and its effect on firm performance. In: Information \& Management, n. 39, p. 41-52, 2003.

COOK, M.; FIORENTINO, G.; CAROLINSK, J. Os elos mais fracos da cadeia logística. In: Valor Econômico, 20/03/2002. Disponível em <www. valor.com.br>. Acesso em: 17 abril 2007.

DIAS, R.; PITASSI, C.; JOIA, L. Gestão integrada da cadeia de suprimentos. Rio de Janeiro: FGV, EBAPE, 2003.
FAIRBANKS, M. Capacidade produtiva cresce para acompanhar clientes. In: Química e Derivados on Line, v. 439, abril 2006.

FELDENS, L. Impacto da Tecnologia da Informação nas variáveis estratégicas organizacionais na gestão da cadeia de suprimentos. Porto Alegre. Dissertação (Mestrado em Administração) - PPGA, Escola de Administração, UFRGS, 2005.

GUNASEKARAN, A.; NGAI, E. Information systems in supply chain integration and management. In: European Journal of Operational Research, v. 159, p. 269-95, 2003. 
HALEY, G.; KRISHNAN, T. It is time for CALM: computer aided logistics management. In: International Journal of Physical Distribuition \& Logistics Management, v. 25, n. 4, p. 97-112, 1995.

MELLO, L. Seis Sigma: análise metodológica de implantação em uma empresa industrial. Niterói: Dissertação (Mestrado em Engenharia de Produção) - PPGEP, Escola de Engenharia, UFF, 2003.

MELLO, L.; BANDEIRA, R., LEUSIN, S. Analisando uma proposta de alinhamento entre o suprimento e a demanda: o caso do setor de gases industriais no Brasil. In: Produção on line, v. 6, n. 1, 2006.

NEIROTTI, P.; PAOLOCCI, E. Assessing the strategic value of Information Technology: an analysis on the insurance sector. In: Information \& Management, v. 44, p. 568-82, 2007.
NOVAES, A. Logística e gerenciamento da cadeia de distribuição. Rio de Janeiro: Campus, 2004.

OLIVEIRA, M.; MAÇADA, A.; GOLDONI, V. Análise da aplicação do método estudo de caso na área de sistemas de informação. Anais do 30 Encontro da Anpad Congresso, Salvador, 2006.

PACHIONE, R. Especialização é a tática da moda do setor. In: Química e Derivados on line, v. 420, 2003.

PATTERSON, K., GRIMM, C. \& CORSI, T. Adopting new technologies for supply chain management. In: Transportation Research Part E, v. 39, p. 95-121, 2003.
SEROPPIAN, I. Investment in supply chain management applications to grow 5\% in 2004. Nova lorque: AMR Research Press Release, 2004.

TORKZADEH, G. e DOLL, W. The development of a toll for measuring the perceived impact of information technology on work. In: OMEGA, v. 27, p. 327-339, 1999.

TRIVIÑOS, A. Introdução à pesquisa em ciências sociais. São Paulo: Atlas, 1987.

WU, F., YENIYURT, S., KIM, D. \& CAVUSGIL, S. The impact of information technology on supply chain capabilities and firm performance: a resource-based view. In: Industrial Marketing Management, v. 35, p. 493-504, 2005.

YIN, R. Estudo de caso: planejamento e métodos. Porto Alegre: Bookman, 2001.

\section{SOBRE OS AUTORES}

\section{Renata Albergaria de Mello Bandeira}

Escola de Administração /PPGA/UFRGS

End.: Rua Washington Luiz 855 - Centro - CEP 90010-460 - Porto Alegre - RS - Brasil.

Tel: + 55 (51) 3330-3366 Fax: + 55 (51) 3220-6472

E-mail: re.albergaria@gmail.com

\section{Antonio Carlos Gastaud Maçada}

Escola de Administração /PPGA/UFRGS

End.: Rua Washington Luiz 855, sala 317 - Centro - CEP 90010-460 - Porto Alegre - RS - Brasil

Tel: + 55 (51) 3316-3833 Fax: + 55 (51) 3316-3833

E-mail: acgmacada@ea.ufrgs.br 